\title{
Primary pain generator identification by CT-SPECT in a patient with low back pain: a case report
}

\author{
Gabriel Tender ${ }^{1 *}$, Adriana Constantinescu ${ }^{2}$, Andrew Conger ${ }^{1}$ and Anthony DiGiorgio ${ }^{1}$
}

\begin{abstract}
Background: Chronic low back pain is one of the most common conditions encountered in the middle-age population. Identifying the primary pain generator is notoriously difficult. The computed tomography-single-photon emission computed tomography (CT-SPECT) is emerging as a new diagnostic modality for this purpose.

Case presentation: This 68-year-old Caucasian male presented with intractable low back pain refractory to maximal conservative treatment, including medication and extensive physical therapy. The lumbar computed tomography, magnetic resonance imaging, and flexion-extension X-rays showed advanced degenerative changes throughout the lumbar spine, but no single level significantly worse than the others. The CT-SPECT showed markedly increased uptake at the L1-2 disc level and only minimal uptake at the other levels. The patient underwent a minimally invasive lateral L1-2 fusion with near-complete resolution of his low back pain.
\end{abstract}

Conclusions: The CT-SPECT may provide a unique tool in establishing the primary pain generator in patients with degenerative spine disease.

Keywords: CT-SPECT, Degenerative spine, Low back pain, Primary pain generator

\section{Background}

Low back pain (LBP) is the most common cause of disability between the ages of 20 and 45 in the United States [1]. While the initial episodes of LBP are usually transient and respond well to non-steroidal anti-inflammatory medication and physical therapy, the natural progression of degenerative spine disease is towards chronic axial pain, with or without radiculopathy, depending on the degree of associated lateral recess and/or foraminal stenosis. However, it is extremely difficult to pinpoint the primary pain generator in patients with such complex spine pathology. Common investigations include, in increasing order of complexity, flexion-extension X-rays (which may demonstrate instability), CT (which may determine bony abnormalities), and MRI (which may identify disc and/or facet joint pathology, among other

\footnotetext{
*Correspondence: gtende@lsuhsc.edu

${ }^{1}$ Department of Neurosurgery, Louisiana State University, 2020 Gravier Street, Suite 744, New Orleans, LA, USA

Full list of author information is available at the end of the article
}

things). Other diagnostic tools, such as discography, attempt to recreate the patient's "usual" pain by injecting the respective disc with contrast media under pressure [2]. Unfortunately, discography has significant drawbacks and may actually accelerate disc degeneration. While these tests may show structural abnormalities, no single test has reliably predicted the primary pain generator.

Single-photon emission computed tomography (SPECT) uses detection of 99mTc-Technetium bound to osteoblasts [3] to gain information on the amount of bone remodeling activity in the spinal axis. Using imaging merging software between the SPECT and CT, we can thus identify with a high degree of anatomic precision which parts of the spine exhibit increased osteoblastic activity. This activity may be indicative of pain generation $[4,5]$.

We report an illustrative case of a patient whose pain source could not be identified by the traditional imaging techniques. The primary pain generator was identified by CT-SPECT and treated by a minimally invasive spinal 
fusion, which relieved the pain and thus confirmed the diagnosis.

\section{Case presentation}

A 68-year-old Caucasian man presented with several years history of low back pain, occasionally radiating to the left lower extremity. The pain was described as 10/10 in intensity (on the Visual Analog Scale, with $1=$ no pain and $10=$ the worst pain ever experienced), incapacitating, improved in supine position and increased by walking or standing. The patient has already tried extensive conservative treatment, including medication (non-steroidal anti-inflammatories such as ibuprofen and naproxen, occasionally oral opioids such as oxycodone/ acetaminophen, and muscle relaxants such as cyclobenzaprine) and physical therapy, with minimal relief. His past medical and surgical history was significant for hypertension and depression, and a thoracic 11-12 laminectomy and fusion about 8 years prior to presentation, respectively. The patient had a 15-pack-year history of smoking cigarettes, but had quit smoking 20 years prior to presentation. The neurological examination was normal. Preoperative routine laboratory tests: complete blood count $(\mathrm{CBC})$, basic metabolic panel (BMP), prothrombin time (PT), partial thromboplastin time (PTT), and urinalysis (UA) were normal.

The flexion-extension and lateral bending lumbar $\mathrm{X}$-rays revealed extensive degenerative changes in the lumbar spine, but no grossly abnormal motion. A lumbar CT confirmed the loss of disc height at all lumbar levels and sclerotic changes, particularly at L1-2 and L2-3 (Fig. 1). The MRI confirmed the CT findings and also showed multi-level foraminal stenosis, but no critical central canal stenosis (Fig. 2).

The patient was advised regarding the results of imaging and was told that, based on the available information, we could not reliably identify a single pain generator. A CT-SPECT was obtained and demonstrated significantly increased uptake at the L1-2 disc level, with only minimal uptake at the other degenerated levels (Fig. 3). The patient underwent a lateral retroperitoneal/retropleural approach for a minimally invasive L1-2 interbody fusion with lateral plate (Fig. 4). At the 3-month postoperative visit, the LBP decreased to $1 / 10$ on the average and $2 / 10$ at its' worst, and these results were maintained at patient's last clinic visit, 12 months after the surgery. The usage of Percocet ${ }^{\circledR}$ (oxycodone $10 \mathrm{mg}+$ acetaminophen $^{-}$ $325 \mathrm{mg}$ ) decreased from 3 to 4 per day before the surgery to occasionally one per week at 3-months postoperatively. The rest of medication (aspirin, lovastatin, amlodipine) usage remained the same.

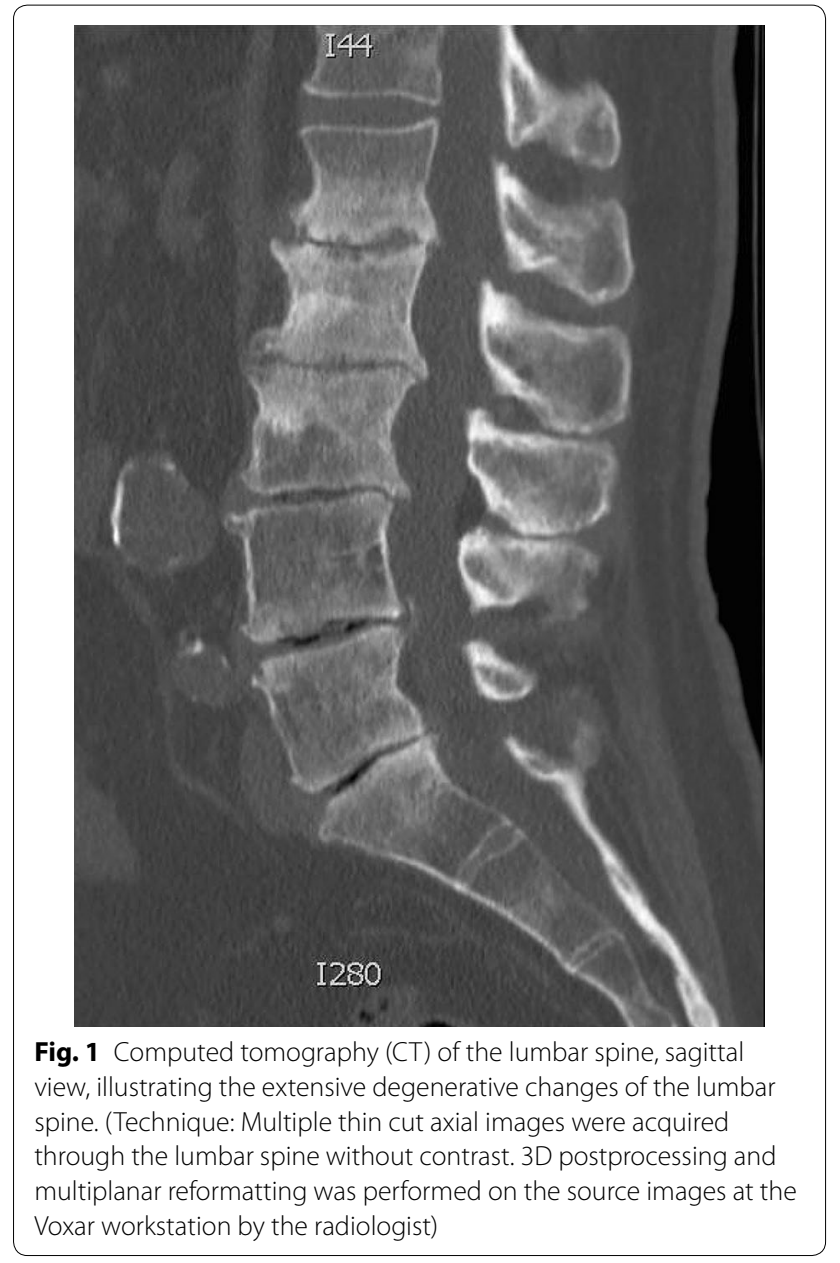

\section{Discussion}

SPECT has been used for several decades to identify bone abnormalities [6]. Recently, clinicians have started to combine the functional value of SPECT with the anatomical accuracy of $\mathrm{CT}$, in order to determine the potential pain generators and treatment targets [7-9].

Identifying the primary pain generator in patients with degenerative spine pathology makes the difference between therapeutic success and failure. Surgical fusions may provide superior results compared to medical treatment in patients with an obvious primary pain generator (e.g., spondylolisthesis) [10]. The situation is different in patients with extensive degenerative spinal changes, with no particular segment significantly worse than the others. In these patients, the traditional options are either conservative treatment or extensive surgery that would address all the levels, but would also incur tremendous risks. We believe that CT-SPECT provides a major diagnostic advantage and may offer these patients a third 

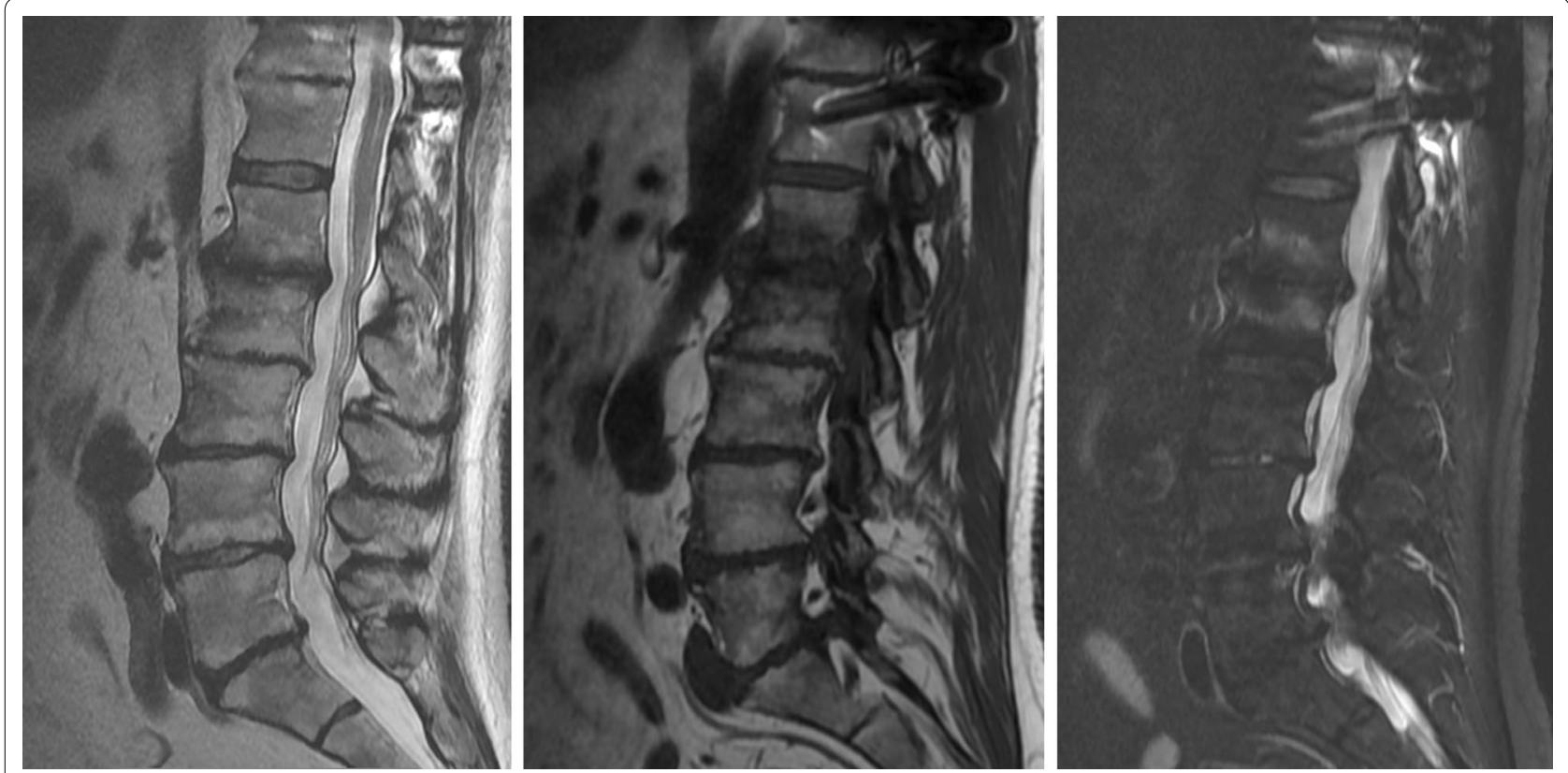

Fig. 2 Magnetic resonance imaging (MRI) of the lumbar spine. Left sagittal T2-weighted, center sagittal T1-weighted, and right sagittal T2 with fat suppression images, confirming the advanced degenerative changes, but without any critical central canal stenosis (technique: sagittal images were obtained with fast-spin echo T1-weighting, T2 weighting, and T2 with fat suppression. Axial fast-spin echo T2 weighted images were also obtained)
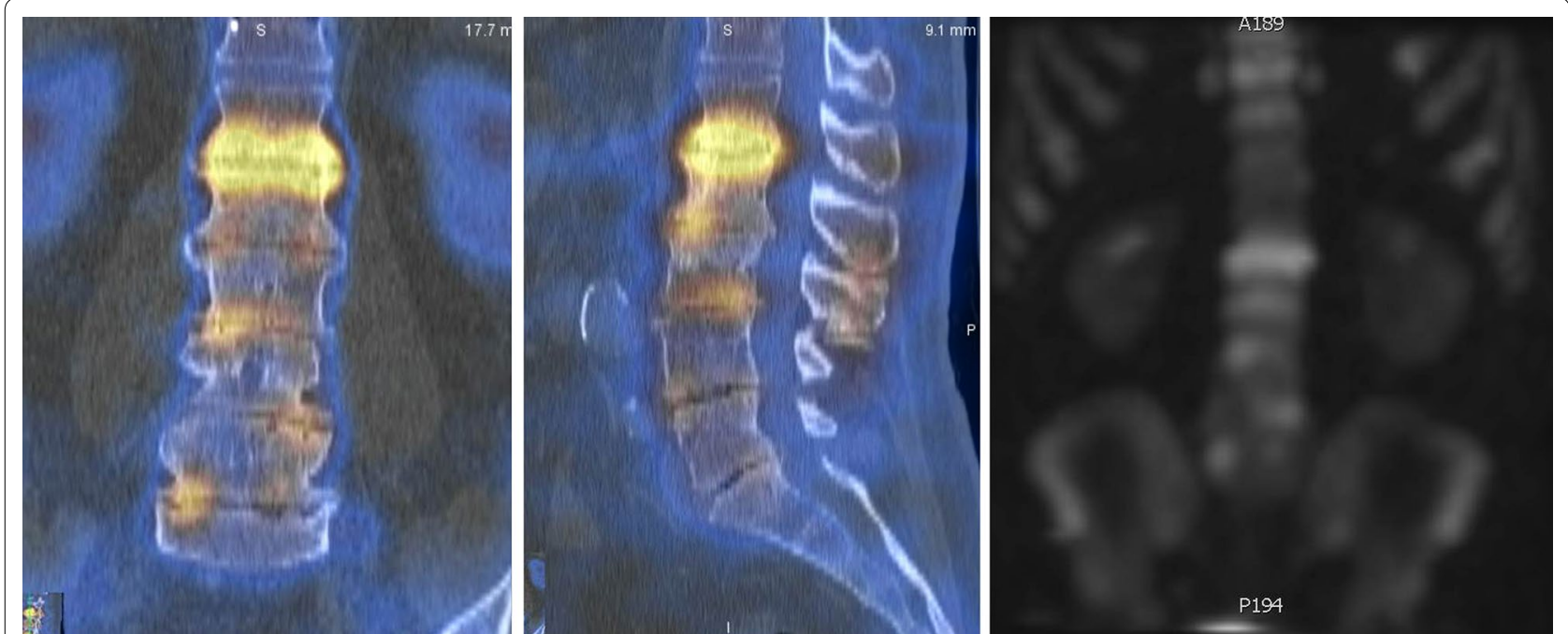

Fig. 3 CT-SPECT of the lumbar spine. Left coronal and center sagittal merged images show increase Technetium uptake at the L1-2 level and minimal uptake at the other levels. Right the whole body bone scan (technique: $33.4 \mathrm{mCi}$ of Technetium 99m MDP were administered intravenously. Bone scan images with SPECT imaging was obtained of the lumbar spine. These images were fused to CT lumbar spine of same date)

option. If the CT-SPECT identifies only one or two levels with increased activity, which can be treated by a much smaller operation, we may provide the desired pain relief with minimal associated morbidity.
As previously demonstrated, the SPECT is based on 99mTc-Technetium uptake by the osteoblasts [3]. The study will obviously show increased activity at sites where the bone is attempting to grow, such as fractures 

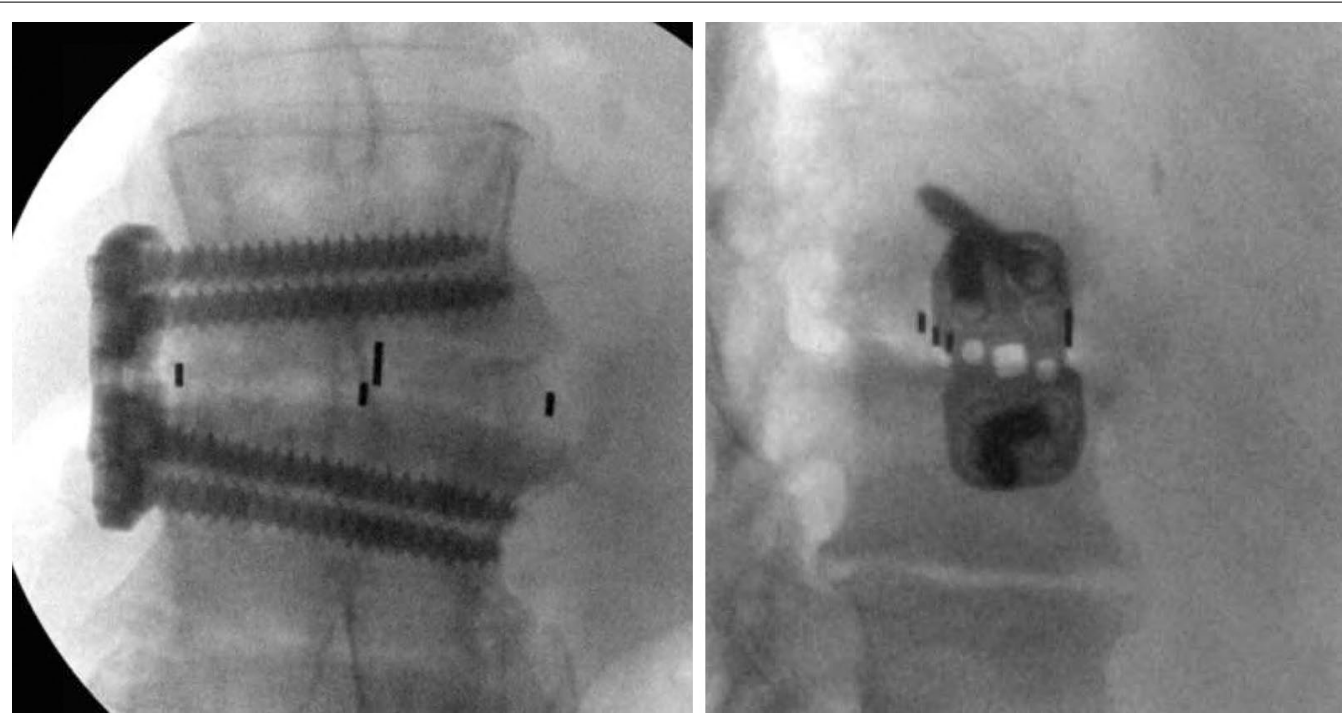

Fig. 4 Postoperative X-rays of the lumbar spine. Left antero-posterior and right lateral images illustrating the L1-2 interbody spacer with a lateral plate

or postoperative fusion sites. However, the SPECT will also show increased activity at sites that have abnormal motion, which the body tries to spontaneously fuse, in order to stop the abnormal motion and hence the pain. We are in the process of conducting a prospective study to evaluate the sensitivity and specificity of this test for patients with pain of spinal origin. In the reported case, the CT-SPECT was the only study that could positively identify the primary pain generator, and this was confirmed by the near-complete pain relief after surgical fusion of that segment.

\section{Conclusions}

The CT-SPECT may provide a unique diagnostic advantage over the current modalities in identifying the primary pain generator in patients with pain of degenerative spinal origin.

\section{Abbreviations}

CT-SPECT: computed tomography-single-photon emission computed tomography; CT: computed tomography; MRI: magnetic resonance imaging: LBP: low back pain; CBC: complete blood count; BMP: basic metabolic panel; PT: prothrombin time; PTT: partial thromboplastin time; UA: urinalysis.

\section{Authors' contributions}

GT performed the operation, all authors discussed and analyzed the patient data; $A C, A C$ and $A D$ were major contributors in writing the manuscript; all authors have read and approved the final manuscript.

\section{Author details}

${ }^{1}$ Department of Neurosurgery, Louisiana State University, 2020 Gravier Street, Suite 744, New Orleans, LA, USA. ${ }^{2}$ Department of Oncology, University of Craiova, Str. Alexandru loan Cuza, 200585 Craiova, Romania.

\section{Acknowledgements}

None.

\section{Competing interests}

The authors declare that they have no competing interests.

\section{Availability of data and materials}

The data and materials used in this article are available by request from the corresponding author (e-mail: gtende@|suhsc.edu)

\section{Consent}

Written informed consent was obtained from the patient for publication of this case report and accompanying images. A copy of the written consent is available for review by the Editor-in-Chief of this journal.

\section{Ethics approval and consent to participate}

This case report is part of an ongoing research study approved by the Louisiana State University Institutional Review Board and the Touro Hospital Ethics Committee. The patient consented to participate in the study.

Received: 29 January 2016 Accepted: 17 March 2017

Published online: 21 March 2017

\section{References}

1. Vos T, Flaxman AD, Naghavi M, Lozano R, Michaud C, Ezzati M, Shibuya K, Salomon JA, Abdalla S, Aboyans V, et al. Years lived with disability (YLDs) for 1160 sequelae of 289 diseases and injuries 1990-2010: a systematic analysis for the Global Burden of Disease Study 2010. Lancet. 2012;380:2163-96.

2. Smith JS, Sidhu G, Bode K, Gendelberg D, Maltenfort M, Ibrahimi D, Shaffrey $\mathrm{Cl}$, Vaccaro AR. Operative and nonoperative treatment approaches for lumbar degenerative disc disease have similar long-term clinical outcomes among patients with positive discography. World Neurosurg. 2014;82:872-8.

3. Zhong ZA, Peck A, Li S, VanOss J, Snider J, Droscha CJ, Chang TA, Williams BO. $(99 \mathrm{~m}) \mathrm{TC}$-methylene diphosphonate uptake at injury site correlates with osteoblast differentiation and mineralization during bone healing in mice. Bone Res. 2015;3:15013.

4. Papathanassiou D, Bruna-Muraille C, Jouannaud C, Gagneux-Lemoussu L, Eschard JP, Liehn JC. Single-photon emission computed tomography combined with computed tomography (SPECT/CT) in bone diseases. Joint Bone Spine. 2009;76:474-80.

5. Trout AT, Sharp SE, Anton CG, Gelfand MJ, Mehlman CT. Spondylolysis and beyond: value of SPECT/CT in evaluation of low back pain in children and young adults. Radiographics. 2015;35:819-34. 
6. Gates GF. SPECT bone scanning of the spine. Semin Nucl Med. 1998;28:78-94.

7. Carstensen MH, Al-Harbi M, Urbain JL, Belhocine TZ. SPECT/CT imaging of the lumbar spine in chronic low back pain: a case report. Chiropr Man Therap. 2011;19:2.

8. Harisankar CN, Preethi GR, George M. Hybrid SPECT/CT evaluation of dual ectopia of thyroid in the absence of orthotopic thyroid gland. Clin Nucl Med. 2012;37:602-3.
9. Lee I, Budiawan H, Moon JY, Cheon GJ, Kim YC, Paeng JC, Kang KW, Chung JK, Lee DS. The value of SPECT/CT in localizing pain site and prediction of treatment response in patients with chronic low back pain. J Korean Med Sci. 2014;29:1711-6.

10. Weinstein JN, Lurie JD, Tosteson TD, Hanscom B, Tosteson AN, Blood EA, Birkmeyer NJ, Hilibrand AS, Herkowitz H, Cammisa FP, et al. Surgical versus nonsurgical treatment for lumbar degenerative spondylolisthesis. N Engl J Med. 2007;356:2257-70.

\section{Submit your next manuscript to BioMed Central and we will help you at every step:}

- We accept pre-submission inquiries

- Our selector tool helps you to find the most relevant journal

- We provide round the clock customer support

- Convenient online submission

- Thorough peer review

- Inclusion in PubMed and all major indexing services

- Maximum visibility for your research

Submit your manuscript at

www.biomedcentral com/submit 